Eastern Illinois University

The Keep

Faculty Research and Creative Activity

Kinesiology \& Sports Studies

October 2011

\title{
Categorical Shortcomings: Application, Adjudication, and Contextual Descriptions of Game Rules
}

\author{
Chad R. Carlson \\ Eastern Illinois University, ccarlson@eiu.edu \\ John Gleaves \\ California State University - Fullerton
}

Follow this and additional works at: http://thekeep.eiu.edu/kss_fac

Part of the Kinesiology Commons

\section{Recommended Citation}

Carlson, Chad R. and Gleaves, John, "Categorical Shortcomings: Application, Adjudication, and Contextual Descriptions of Game Rules" (2011). Faculty Research and Creative Activity. 5.

http://thekeep.eiu.edu/kss_fac/5 


\section{Categorical Shortcomings: Application, Adjudication, and Contextual Descriptions of Game Rules}

\section{Chad Carlson and John Gleaves}

In the final extra time minutes of the 2010 World Cup quarterfinal match between Uruguay and Ghana, Uruguay's star striker Luis Suárez deliberately batted the ball with his hand off of his own team's goal line. The referee quickly detected his action, penalizing Suárez with a red card for deliberately handling the ball and rewarding Ghana with a penalty kick. Given that he had no other way to stop the ball and with only seconds remaining, his decision appeared-despite the odds-to be a calculated one. Had Suárez not stopped the ball, Uruguay's World Cup run was over. Even with the impending penalty kick, Uruguay's chances of winning were slim but not impossible. Yet when Ghana's Asamoah Gyan failed to convert the subsequent penalty kick, Suárez's "deal with the devil" turned into either an act of strategic brilliance or the mischievous manipulation of a loophole in soccer rules.

Suárez's actions raise questions about games and their rules. He openly violated the rules and willingly accepted his punishment, yet he also broke the rules in order to deny Ghana a fair and earned victory. So his case indicates a larger problem-what to make of this type of egregious but strategic rule breaking. To better understand the appropriateness of Suárez's actions, one needs to understand the more fundamental relationship between games and their rules. And it is here that, despite much effort, the field of sport philosophy is still without a satisfactory paradigm that explains game rules.

The existing paradigm focuses mainly on a categorical distinction developed by John Searle between constitutive rules that make the convention possible by determining relationships where none existed before, and regulative rules that identify relevant existing relationships and regulate behavior. This constitutive/ regulative categorical distinction has a number of clear uses. It can help us understand the need for rules to define practices like sports. It also indicates that some connection exists between sports and potentially incompatible rule violations. But it still remains unclear whether the constitutive/regulative distinction adequately provides a rough account of game rules or even if it sufficiently explains the relationship between games and their rules. More importantly, can such an account of game rules actually help us to evaluate a player's behavior in relation to a game's

The authors<crc214@psu.edu> are with the Dept. of Kinesiology, Pennsylvania State University, Altoona Campus, Altoona, PA (Carlson) and the Dept. of Kinesiology, California State University, Fullerton, Fullerton, CA (Gleaves). 
rules? Can we apply an understanding of game rules predicated on constitutive and regulative categories to make sense of ambiguous situations such as Suárez's actions and his subsequent penalization?

Our goal in this paper is not to make ethical arguments regarding Suárez's case. Rather we are proposing a new way of looking at game rules that will have implications for how we understand complex sporting situations. Broadly, how we understand game rules affects not just the metaphysics of games but also how we conceive of ethical behavior in sport (such as when evaluating Suárez's actions), the role of officials in adjudicating decisions, the nature of sport in society, and the value of sport in physical education. For example, we hope to show that the problem posed by Russell's question "are the rules all an umpire has to work with?" becomes less troublesome when we study rules from a different context than that which the existing literature provides (9). To examine these questions, we will briefly present Searle's original categorical distinction. Next, we will argue that scholars have thus far reached little consensus regarding the nature of constitutive and regulative rules. We show that, in the existing literature, the categorical distinction is not as neat as scholars have thus far suggested and that, perhaps, a more fundamental problem in this approach may lurk under the surface. We conclude that, though something can be made of the constitutive/regulative distinction of rules in sports, the distinction often blurs, leaving us with a continuum of rules-some more constitutive than others, some close and some far from the core features of the games that they define. Given this critique of the constitutive/regulative distinction in the sport philosophy literature, we conclude that this categorical paradigm for describing game rules cannot satisfactorily help philosophers of sport resolve many of the complex issues involving the application, interpretation, adjudication, or manipulation of a game's rules. In that way, we propose a new paradigm for evaluating actions-like Suárez's handball — that do not conform to strict categorical distinctions.

\section{Discussion of Pertinent Rules Literature}

Rules are the building blocks of games. Philosophical inquiry into rules potentially offers significant insights regarding new or developing game problems. Heretofore, scholars have primarily sought to explain game rules through a Searlean constitutive/regulative distinction. While there is no evidence that some of the key contributions to the sport philosophy discussions of rule categorization owe any debt to Searle-even Searle admittedly transferred Kant's constitutive/regulative distinction to rules in a 1964 article and subsequent book chapter-most authors cite Searle's work prominently and all of them use at least some of the same terminology. ${ }^{1}$ Searle's work often cited game rules to explain the operation of rules in language. Philosophers of sport, perhaps noting the acuity of Searle's game examples, began using Searle's distinction between constitutive and regulative rules, or at least this Kantian language, to describe the actual operation of rules within games (10). Scholars such as Bernard Suits, Fred D'Agostino, Gordon Reddiford, Klaus Meier, William Morgan, Cesar Torres, and R. Scott Kretchmar incorporated Searle's terminology into their sport analyses. ${ }^{2}$

The degree that sport philosophers use Searle's language shows the method's influence on how we understand rules in sport. Bernard Suits used similar language to describe games in his seminal metaphysical work while sport ethicists such as 
Sigmund Loland and Robert Simon used the categorical/regulative distinction to explain sport ethics that resulted in the philosophies of essentialism, conventionalism, and broad internalizm $(4,12,13)$. Furthermore, Graham McFee used Searle's categories, albeit critically, at the beginning of his epistemological and axiological analysis of rule following (5). Certainly sport philosophers found in Kant and Searle an approach to studying rules that has inspired a great deal of thinking.

Ultimately, Searle's contribution to game rule literature hinges on the constitutive/regulative distinction. He explains that languages have constitutive rules that "create or define new forms of behavior, and ... have the form: $\mathrm{X}$ counts as $\mathrm{Y}$ in context C" (11: p. 35). For Searle, these newly created forms of behavior include sets of circumstances that would direct game players to avoid committing a handball penalty, pursue checkmate in chess, or score a goal in soccer. Such forms of behavior would be unintelligible outside the context of a particular game's set of constitutive rules. Moreover, Searle explains that "constitutive rules constitute (and also regulate) an activity whose existence is logically dependent on the rules" (11: p. 34). Thus constitutive rules are only intelligible within the conventions of games while the games become intelligible through their constitutive rules.

Searle's regulative rules, on the other hand, "regulate antecedently or independently existing forms of behavior" (in the forms: "Do X"; or, "If Y do X"). These rules "regulate a pre-existing activity whose existence is logically independent of the rules" (11: p. 34). As such, they differ from constitutive rules. They do not create or define new behavior only understood within the context of the game like constitutive rules. Instead, they support constitutive rules by explaining behaviors that aid in successful occurrences of the games. That is, when behavior accords with a regulative rule, the behavior can be given the same description or specification with or without using any particular rule. Regulative rules in games specify strategies (add defenders when winning late in a game), techniques (keep one's knee over the ball when shooting on goal), procedures (shake hands with opponents before and after games), and natural facts (a ball kicked with spin will curve away from the side on which it was struck).

Bernard Suits published his first discussions of games and their rules around the same time as Searle. Suits explains that there are two kinds of rules: constitutive rules and rules of skill. He defines constitutive game rules similar to Searle by implicitly claiming that they create new forms of behavior. Constitutive rules, to Suits, "prohibit use of the most efficient means for reaching a ... goal" and they "set out all the conditions which must be met in playing the game" (13:p. 37). Suits then makes a parenthetical caveat to his constitutive rules, explaining that there is also a subset of rules that are extensions of constitutive rules. He argues that the breaking of these rules is strategic in nature and carries with them fixed penalties, such as the intentional foul in basketball or Suárez's handball in soccer (13).

Suits' second category, rules of skill, explains how to play the game well. Rules of skill lack coercive force in that a failure to comply with them is simply a failure to play the game well (kick with the laces to shoot a soccer ball, for example). Although not necessarily written into rule books, rules of skill influence how players play the game (13). Searle included these rules in his regulative category-a grouping that Suits does not address or at least downplays.

Following Suits, D'Agostino marked the next significant shift in rules literature (1). D'Agostino uses the Searlean constitutive/regulative distinction to show the 
indefensibility of formalistic accounts of games. That is, he explains that formalism with a rigid dichotomy between constitutive and regulative rules has indefensible "Platonistic implications" (1: p. 45). However, he understands constitutive and regulative rules differently than Searle and Suits by saying that the former define the game and the latter are penalty-invoking rules. With this new understanding, D'Agostino suggests a different account of game rules. Instead of formalism, which distinguishes only between permissible and not permissible behavior (what he refers to as the regimented or dichotomized categories of constitutive and regulative rules), he suggests that a conventionalist approach might be more defensible. In this ethos-oriented approach, D'Agostino does not explicitly use Searle's constitutive/ regulative terminology as he describes three categories of game behaviors as those which are permissible, impermissible but acceptable, and unacceptable. Further, he acknowledges that there is an "implicit set of conventions" in each sport that helps to distinguish between each of the three categories (1: p. 46).

Reddiford conjures up the next attempt to clarify categories of game rules (8). He argues for an altogether different relationship than Searle, Suits, and D'Agostino regarding constitutive and regulative rules. For Reddiford, the constitutive and regulative distinction is not central to understanding games. Instead, he offers a different description of constitutive rules. Rather than creating or defining new forms of behaviors in games, they "create the possibility of new descriptions of behavior" (8: p. 44). Playing codified games of soccer does not create new behaviors so much as give new meaning to presoccer behavior (frivolously kicking a ball), a type of activity that is still a part of the institution, or overall culture, of soccer.

After Reddiford, Meier goes in a different direction than previous authors regarding constitutive/regulative distinctions. Meier proclaims that "it is by no means clear that an absolute dichotomization [between constitutive and regulative rules] may be supported" (6: p. 69). Instead, he believes, unlike Reddiford or D'Agostino, that "[regulative] rules are perhaps best viewed as extensions, or as a subset of constitutive rules rather than as indicators of the termination, however temporary, of the 'constitutional internalities' of playing the game" (6: p. 69). Suits also referred to a subset of constitutive rules, but he did not label this smaller group.

According to Meier, both constitutive (try to score goals) and regulative rules (but do not use your hands when doing so) are instantiated "during the occurrence of the game" (6: p. 70), and can be explained together within the game. However, Meier also believes that some rules are neither constitutive nor regulative. To accommodate this, Meier adds a new category of rules that he names "auxiliary rules." 3 Although this group has some overlap with Searle's description of regulative rules, Meier does not make that connection. Instead he says that this group of rules, such as the ones that spelled out Suárez's disqualification from the current and following game after his handball, "specifies and regulates eligibility, admission, training and other pre-contest requirements," and "is of a different color or nature entirely than constitutive rules and, as such, has nothing whatsoever to do with the essence of sport" (6: pp. 70-71). Meier seems to say that auxiliary rules, while important, are not necessary for the game to occur.

Morgan, in the next article on game rules, views constitutive rules as more central and prominent than any other author since Suits. He declares that con- 
stitutive rules are those "upon which the very existence of the game is logically dependent," and they are "to be distinguished from another kind (regulative rules) which regulates antecedently or independently existing forms of behavior, and to which specific penalties are attached" (7: p. 51). This sounds Searlean, but Morgan adds caveats that make his interpretation different. He says that "regulative rules presuppose the existence of constitutive rules (without which there would be nothing to regulate), and so count as extensions of the latter" (7: p. 51). Clearly such a claim is not at all Searlean because Searle's regulative rules do not presuppose constituted forms of behavior. Instead Morgan seems to follow Suits and Meier in this line of thinking.

More specifically, while Morgan and Searle believe that regulative rules regulate behavior, Morgan sees regulative rules more particularly as those which invoke penalties. In Searle's view, constitutive rules create or define new forms of behavior and regulative rules regulate antecedently-existing conditions. Morgan, on the other hand, concludes that constitutive rules "regulate in a more primary sense, and without the pain of penalty" and regulative rules are penalty-invoking (7: p. 53). ${ }^{4}$

Like some of his predecessors but unlike Morgan, Torres sees a great deal of overlap between constitutive and regulative rules. However, instead of naming regulative rules as extensions of constitutive rules, he discusses the reality of constitutive/regulative hybrids. He states that "the dichotomy between constitutive and regulative rules is ... complicated by the fact that some regulative rules are not only nested in conventions but also have quasi-constitutive connotations and functions" (14: p. 82).

Torres clearly understands that the distinction is imperfect, but like many other authors, he continues to use it. ${ }^{5}$ In order to clarify the relationship between different types of rules, he offers two amendments that more closely identify the functions of particular sets of rules. First, Torres amends Searle's definition of constitutive rules, instead describing them as lusory enactors - or those rules that enable new behaviors, such as the edict to use any part of one's body to score except the hands or arms. Second, he uses the term "lusory restorers" to explain what Morgan and others saw as regulative rules-rules that regulate constitutive behaviors, such as the referee awarding a penalty kick to Ghana and a red card to Suárez in an attempt to restore fairness in the game (14: p. 83).

Lastly, Kretchmar realized the degree to which scholars deviated from Searle's original positions and attempted to clarify Searle's constitutive/regulative distinction by redirecting our attention back to Searle's own words. He upholds Searle's description of constitutive rules as those that "create or define new forms of behavior," despite modification attempts by many of the aforementioned authors. More importantly, he clarifies Searle's position on regulative rules, stating that "for Searle, then, regulative rules do not specify penalties. (A subset of constitutive rules ... do that.) Rather, regulative rules operate outside of and, at least potentially, prior to and during the formation of conventions" (3: p. 163). Thus, Kretchmar understands that Searle and some of the scholars mentioned are pointing to two different distinctions when they employ the constitutive-regulative terminology. While his viewpoint varies greatly from the others, Kretchmar continues to use the constitutive/regulative paradigm to explain the nature of game rules. 


\section{Analysis of the Categorical Method}

So what lessons can we draw from the preceding literature review? First, and most importantly, the categories provided by this literature have not produced a definitive paradigm to understand game rules in general or Suárez's actions in particular. Did Suárez violate one of Searle's constitutive rules? It would initially seem so since not using one's hands defines the sport. Yet the categorical paradigm does not account for differences within the constitutive category. Surely Suárez's handball occurred in a context that included important differences from ordinary or incidental handball penalties, yet this paradigm is unable to handle the intracategory variability. At the same time, Suárez's violation, even though it directly affected the outcome of the game, may concurrently fit into seemingly more peripheral categories such as Suits' subset that is an extension of constitutive rules, Meier's regulative rules, or Torres' lusory restorers. With this messy experiential reality of what seem to be fairly clean and distinct categories, the current paradigm provides little help in analyzing the place of game adjudication, rule following, rule breaking, and the playing of games.

Additional lessons also emerge that provide reason to question the usefulness of the categorical distinction. Many differing conceptions of Searle's distinction between constitutive and regulative rules exist. Given such discrepancies, scholars cannot assume one standard definition exists for constitutive and regulative rules. While Kretchmar's clarification of Searle's original distinction between constitutive and regulative rules reinforces Searle's initial point, it also serves to highlight the various directions taken by different scholars. For example, Suits describes constitutive rules (and a corresponding unnamed subset) in his own way without explicitly referencing regulative rules. D'Agostino believes that only two distinct and dichotomized categories of rules (constitutive and regulative) make games too formalistic. Instead he offers three categories of game behaviors (permissible, impermissible but acceptable, and unacceptable) that are governed by social conventions (and a certified official, of course). Reddiford also takes little interest in the constitutive-regulative distinction, and he redefines constitutive rules to promote pregame behaviors (a grouping that Searle would have called regulative). Meier dismisses the possibility of dichotomizing between constitutive and regulative rules and takes a Suitsean turn to say that regulative rules are extensions of constitutive rules while also adding a new category (auxiliary rules). Morgan believes that constitutive rules are the central features of games while regulative rules differ in that they invoke penalties. Torres then asserts a need for distinguishing between lusory enablers and lusory restorers but describes a complex relationship in which some regulative rules serve constitutive functions or purposes. Although these scholars all use the constitutive/regulative terminology, it is obvious that each of them interprets or builds on Searle's distinction differently.

These differing accounts have resulted in a metaphysical stalemate with each new author going in a seemingly different direction from the others. Although Kretchmar attempted to break this logjam by revisiting Searle's original definitions of constitutive and regulative rules, not all scholars have grabbed onto his "revisited" positions. Instead, some scholars continue to use a version of the constitutive (prescriptions) vs. regulative (proscriptions) distinction that D'Agostino, Meier, Morgan, and Torres discussed. Others more haphazardly select aspects from vari- 
ous stipulated definitions in ways that lead to conceptual confusion. The ultimate result, then, is that when instances like Suárez's handball arise, philosophers using the constitutive/regulative paradigm struggle to explain the connection between games and their rules.

We are left, then, with various frameworks for understanding constitutive and regulative categories of rules but no real way to apply the framework to messy, real-world situations. Perhaps the problem is not a need to more accurately define the categories, as past scholars have attempted. Rather, there is a more fundamental issue derailing this mode of inquiry. While the categorical distinction showed some promise, what the existing scholarship has revealed is that game rules do not fit neatly into categories. The quest for a set of operationally complete categories ultimately squeezes rules into artificial categories that fall frustratingly short of helping us understand complex game issues like that of Suárez. The aforementioned philosophers have defined (and redefined) categories in attempts to match all of our game rules. However, based on the existing pattern of scholarship, we would likely have to continue to redefine existing categories and add new categories to fully and accurately capture the breadth of game rules.

Realistically, the complexity of game rules may make this an impossible task. Through the previous scholarly investigations it seems evident that rules operate more on a continuum, with some being more central to a game and others more peripheral. Some rules seem to wear multiple hats at the same time, perhaps constituting the game and performing auxiliary functions. The method of creating categories and then plugging every rule into one of them appears incapable of ever doing the work that scholars are asking of it.

Moreover, whenever scholars begin to distill the messy world into ordered patterns, they would do well to heed Wittgenstein's warning that whenever we use metaphysics to "grasp the essence of the thing, one must always ask oneself: is the word ever actually used in this way...?" (15: p. 116). As philosophers know, relying too heavily on metaphysical categories or frameworks to explain the meaning or essence of different rules could easily lead to artificiality because the categories do not replicate the rules' actual use in practice. Thus it is difficult, if not impossible, to fit every game rule into a category as rules are often used differently at different times. Certainly scholars have devoted much effort to categorizing rules, having spent decades amending the constitutive and regulative categories as well as adding their own. But by focusing on building categories, we risk losing a description of game rules as they are practiced.

This point is starkly illustrated by the Suárez handball. While the categorical distinction could potentially provide us with some sort of framework for understanding his actions, we ultimately end up forcing aspects of his behavior into categories that may not fully or accurately capture the breadth or complexity of the situation. Scholars using this categorical framework have analyzed our game rules by creating categories and then separating rules into those categories-making everything a "this" or a "that." For instance, Searle would say that the rule forbidding Suárez to use his hands in soccer is constitutive (a "this"); Reddiford would argue instead that Suárez only violated an institutional rule that codified presoccer behavior (a redefined "this"); Morgan would assert that Suárez's penalty for a handball is a regulative rule (a "that"); Meier may argue that the rule preventing Suárez from using his hands is a regulative rule because it is simply an extension of a constitutive 
rule (a redefined "that"); and D'Agostino might claim that Suárez's handling of the ball is an example of behavior in the category he calls "unacceptable" (neither a "this" nor a "that" but an example of an "other").

What is perhaps most frustrating is not the lack of agreement among scholars over the meaning of specific categories but that it is unclear how one would ever go about determining the categorization of Suárez's actions. His handball violation seems to fit into many categories yet at the same time no category seems capable of completely explaining the behavior. This scenario is far more troubling given the range of implications regarding adjudication that follow from the categories. If Suárez violated Searle's "constitutive rule," his actions, despite the punishment, seem far more excusable than if he engaged in D' Agostino's unacceptable behavior. Furthermore, the fact that Torres' lusory restorative skills (those connected to regulative rules) exist to restart play means that we accept that rule-breaking happens in our games, but it does not necessarily mean that Suárez was right to engage in such behavior. Thus scholars and game officials wishing to understand Suárez's actions find that other scholars' writings on constitutive and regulative rules shed only incidental light on the situation with none providing a single concrete paradigm for judging his actions.

The central shortcoming of the categorical approach is that it makes sharp distinctions that do not capture the sense of the rule in its context or actual usage. In other words, when using the categorical approach, philosophers strive for metaphysical or descriptive tidiness that may not accurately portray our messy landscape of experiences. At best, this distinction serves as a rhetorical device designed to point out differences in certain rules but not as an ontological device that reveals the nature of rules. Perhaps, then, a different tactic is needed-a different way of describing game rules. As we shall argue, the descriptive change occurs when scholars shift from viewing these distinctions as metaphysical categories to treating the distinctions as a type of rough shorthand for describing common contextual settings of rules. In the case of game rules, we will argue that the latter may prove to be a more useful distinction.

\section{Understanding Categorical Distinctions as Contextual Descriptions}

In fairness, we acknowledge that not every author undertook the same task in their articles. While some of the scholars focused on particular categories of rules or on interpretations of Searle's constitutive/regulative distinction, many of them made larger arguments that illuminated game issues beyond Searle's rule distinction. However, the existing game rules literature has not addressed this flaw in the categorical method. Instead, the authors have imposed artificial categories of rules onto games-a method that shows neither how we use rules nor does it provide a context that might help us understand rules or adjudicate behavior in specific game situations-such as that of Suárez. The traditional approach of creating categories and then trying to fit the rules into them ignores the complex or multifunctional nature of rules.

Nevertheless, some of the concepts for understanding rules in a different and more accurate way - as contextual descriptions-have been lurking in the exist- 
ing literature. The arguments of Reddiford, Morgan, Torres, and Kretchmar, for example, have encouraged us to ask, when trying to understand rules, why a rule is there (rule parentage), what purpose it serves (rule functionality), and how each rule helps us understand its game (rule importance).

To understand contextual descriptions, one must consider rule parentage. Rule parentage helps us understand a rule's reason for being. These reasons often vary and help explain why rules function in many ways. For example, some rules come into being, as Reddiford noted, to protect or institutionalize our pregame behaviors. We loved the artificial problems presented by using only our feet before we ever had soccer, and so soccer institutionalized the rule that forbids using hands. Other rules have local parentage, such as soccer's relatively loose code of conduct that dates back to its beginnings as a British working class game. Still other rules can reflect physical or natural forces, such as local weather and geography (imagine if soccer stopped like baseball for rain delays). This diverse parentage is not unique to soccer, either. Many sports reflect similar pressures as their rules have come to be in a variety of ways.

Our invocation to heed the parentage of rules when looking at the specific context of each rule's occurrence in games may seem contradictory. ${ }^{6}$ Admittedly, it would be very difficult for a game official to try to identify the parentage of each rule as its adherence or disobedience occurs during the course of the game. Undoubtedly referees, umpires, and other game officials have many more imminent issues with which they must deal. Yet rule parentage may still play a part in the adjudication of a game as it happens, even if it is not at the forefront of an official's in-game thinking. A referee of a youth developmental soccer league may adjudicate the game with an eye toward prioritizing the rules that most effectively promote skill development (Torres' lusory enablers). The referee of an elite professional league may have to develop (or obey) principles of rule adjudication that encourage the entertainment value of the game. Further, referees of adult recreation leagues may find themselves adhering most strictly to the rules that have come about to prevent injuries and physically violent action.

As we delineate rule parentage, it becomes evident that rules have come about and are adhered to by players and officials in a variety of ways. However, the parentage of rules cannot tell the whole story. Rules often come to have different functions once they are put into practice. For example, Torres' description of lusory enabling and lusory restorative rules shows that the same rule can serve the purpose of making sure that the game features the skills it was meant to feature (no hands-use the feet) while also serving the purpose of getting the game back on track after it has broken down (a free kick for a handball). Thus rule functionality also helps us understand some features of a rule's relationship to a game.

Much like the multifunctional rule against handling a soccer ball, consider how uniform or jersey rules in soccer reflect this wide array of functions. At times, the jersey rule in soccer serves as a lusory enabling function as it allows teammates to more easily recognize each other during the speed of the game; it serves a cultural function in that different games have slightly different jersey requirements depending on when, where, and in front of whom the game is being played; and it serves an auxiliary function in big-time soccer as the top leagues allow marketing on jerseys, but only so long as it conforms to the league's liking. 
Marketing nuances of the jersey rule in soccer are not crucial to the game itself. That is, they help us to understand the spectrum of rule importance-our third factor in contextual descriptions - because they matter very little to the game. Indeed, soccer can be played without any rules limiting or requiring marketing on jerseys. In fact, soccer can be played without jerseys. Some recreational soccer games occur with no clothing evidence of who belongs to which team, and others simply require one team to remove their shirts. Kretchmar and Morgan might argue, then, that the jersey rule is not central to the game of soccer, or at least not as central as other constitutive rules. It has some importance, especially when spectators are involved, but it is not necessary for soccer to come off. On the other hand, rules that feature soccer-specific skills, such as those encouraging use of the feet and prohibiting use of the hands, are very important to soccer-especially in and around the goal mouth. Clearly, rules vary between central and marginal importance, yet oftentimes the same rule - as is the case with jerseys — can span much of this spectrum.

In practice, a person needs to know the specific context of the rule, for rules may be understood differently depending on the context. While some rules are hard and fast and should be adhered to at all times-such as soccer's handball rule-the context of the infraction helps to determine the consequences and implications in the particular game and how we value particular aspects of the game in general. When we take into account the parentage, function, and importance of a rule, we are developing an understanding of its context in the game. We propose, then, a method of contextual descriptions, whereby rules are understood via such things as their various parentage, functions, and importance among others. Contextual descriptions help situate individual rules and groups of rules into the broader structure of games and may help us better understand, for instance, Suárez's situation. Rather than seeking to identify the correct category for each rule, our approach investigates rules as they actually occur in practice.

In this approach, to better understand rules, one basically identifies contextual descriptions attached to specific situations. Understanding rules as contextual descriptions points out the need to know more about a game than its list of rules in order to play the game according to its rules. Simply teaching someone a game's constitutive and regulative rules would not necessarily tell a person how to play the game or even how to play it according to the rules. Playing by the rules is much more complex. One must know the context in which rules operate. Legal scholar Ronald Dworkin argues that the acquisition of principles often comes before and can be the foundation for the learning of rules (2). Our identification of parentage, function, and importance could potentially be among the principles that Dworkin would say provide a "gravitational force" for our understanding of game rules (2: p. 115).

Examining the parentage, functionality, and importance of the handball rule in soccer might give gravitational force to how we understand this rule. The parentage of handling a ball is that this rule is what has set soccer apart from other ball games played on foot (rugby and American football, most specifically). Determining not to use the hands has molded the game of soccer to what it is today. Functionally, the handball rule may have some complexity. Handling can become part of a skill function much like Suits' claim not to trump a partner's ace (i.e., use the chest, head, or leg instead of the hand to control high balls-or, more strategically, use any means including handling to prevent a potential game-winning goal). Some may view the rule within the context of constitutive functionality that defines the 
sporting test and should be adhered to, but when examining the foul from a fairness standpoint, others may describe the lusory restorative function of handling as a give-and-take that can be done if one understands the penal consequences. Simon has made headway in this regard by determining a difference between prices and sanctions for breaking a rule (12). Prices are penalties for illegal behavior that often happens incidentally or strategically. Sanctions, however, are penalties for illegal behavior that we never want to occur in games. While some might say that Suárez's action was morally defensible because he made a strategic decision to pay the price for handling the ball, others might say that soccer gamewrights developed a sanction (penalty kick and disqualification) for his behavior because they disapprove of it and never want it to happen.

Looking at a rule's importance might help us sift through the complex functionality of the rule. Clearly, the rule outlawing handling the ball is of central importance to soccer. While we may not be able to give a full and robust continuum of most to least important rules, we seem to intuitively understand where a rule may generally stand. Handballs are important (especially at the end of close games when they affect the outcome of the games). On the other hand, rules governing lusory restorative skills, Torres tells us, are not as central to the game of soccer. Therefore we want to have victory in soccer determined by those who show greater lusory enabling skill while abiding by the most central rules, rather than allowing egregious rule breaking to taint the game enough that it must be determined by more marginal rules that govern lusory restorative skills.

Such a view of rules is not incompatible with Russell's take on Dworkin, integrity, and adjudication of rules in sport. Russell, following Dworkin, argues that a principle of integrity can help us interpret rules when their application is unclear. The principle of integrity essentially holds that rule changes or rule interpretations must be based on the relevant principles of a practice community. It seems as though rule parentage, functionality, and importance are among the relevant contextual characteristics that help us to uphold or determine the integrity of a practice community. Any new interpretation, change or improvement to the rules must fit within the practice's assumed principles. Thus rules are understood as having continuity and officials, gamewrights, or other rule adjudicators ought to interpret rules such that they maintain integrity with past practices.

Russell's adaptation of Dworkin provides officials with a useful framework for adjudicating tough decisions such as the Suárez case. However, Russell's account of integrity does not explain the nature of game rules. Instead, Russell provides an account of how game rules might be applied to game situations. Yet for our purposes, and even the purposes of those scholars who sought categorical distinctions, an understanding of the nature of game rules can better inform the adjudication of issues that relate to values or characteristics central to the game. Nonetheless, Russell's principle of integrity indicates the practical value of understanding contextual descriptions of rules such as parentage, function, and importance that can act as indicators or signposts for philosophers, gamewrights, and officials seeking to interpret game rules. For example, understanding a rule's parentage, functionality, and importance can help a referee delineate the appropriate response or interpretation of a particular behavior or rule violation. It can also help sporting organizations in their role as gamewrights when they are determining if a rule needs to be rewritten to avoid certain kinds of behavior. We argue, accordingly, 
that an official will be in a better position to adjudicate soccer and a gamewright will be in a better position to determine a rule change, for example, if the relevant rules and principles are contextualized with an understanding of the parentage, functionality, and importance of rules.

The existing categorical method does not account for the context of rules. Scholars who made arguments based on Searlean, Kantian, and/or their own categories believed that we could look at a game and determine the categorical designation of its rules. Yet without context, one could not differentiate the varying functions of the jersey rule or Suárez's situation, for instance. Thus rule context provides necessary information as we interpret rules and adjudicate them within games.

A contextual description offers a more accurate-if also messier - understanding of games and their rules. Contextual descriptions identify the ways in which rules relate to the various parentage, functionality, and importance within games. These descriptions often help remind us of the diverse ways that rules have come to operate within games; for Suárez's action would not have been nearly as memorable if it had happened in the opening minutes of an international friendly game. Scholars can also use these contextual descriptions to elucidate how a single rule in a game performs multiple functions. Since in practice a single rule can often function multiple ways, (i.e., both constitutively and regulatively, or by any other term used by previous scholars who wrote about game rules), using descriptions rather than categories provides a series of signposts that assemble a more complete and accurate, albeit less tidy, articulation of rules in games.

This brings us around to a point of agreement with past literature. Although we reject the attempts of many scholars of game rules to label categories of rules, we believe that what they in fact frequently identified are good descriptions of functionality. This shift is both subtle and seismic. It rejects the methodology of Searle et al. as inevitably doomed to failure. At the same time, it resurrects this body of work on game rules, recognizing that such terms work as descriptors that articulate different contexts of rules or the operation that rules perform in games. Turning the various separate categories of rules into signpost-like contextual descriptions, they provide useful shorthand for describing game rules as we experience them. In the case of Suarez, these signposts point us toward various areas for consideration. For example, did Suárez unethically exploit the weakness of the regulative or lusory restorative function in what we consider to be among the most hallowed constitutive behaviors? Should FIFA work to shore up this loophole or acknowledge that such gamesmanship of the rules is acceptable? As philosophers come to better understand the context of various signposts, the signposts can act as reminders for providing clarity on the function of the rule in the game operation which in turn shows the role of rules in games. Once this type of context has been identified, then referees may have a more robust understanding of how game rules and principles should be enforced.

Thus the field of sport philosophy should not abandon using terms such as "constitutive" and "regulative" or even "lusory restorer" and "auxiliary" despite their various stipulations. These terms provide useful nets for catching the sense of rules as they occur. But they are only nets that catch specific senses rather than labels for classes of rules. We would be wrong to conclude that a hard and fast set of auxiliary rules existed. Indeed, Suárez's case illustrates just how problematic such an assumption proves to be. Instead, we must shift how we view the work 
that these terms are doing. Constitutive and regulative do not label classes of rules or get at the essence of rules as some scholars had hoped. Instead, they provide helpful reminders of the contexts by which we most fully understand particular rules-signposts to guide us in studying rules, nets for catching certain senses of rules. While not metaphysically tidy, this conception of rules does provide a more accurate and hopefully more useful paradigm for considering game rules.

\section{Conclusion}

So what lessons can scholars draw from the use of constitutive and regulative rules to evaluate Suárez's actions? These terms can provide a launch pad as descriptors to begin analysis of specific incidents in games, but we need to be careful if we treat them as distinct, rigid categories that name ontological or metaphysical aspects of rules. In that sense, the existing literature can provide some benefit, but as it currently stands, too much conceptual confusion still exists and in many cases the distinction between rules blurs to the point that categories do not appear useful for capturing the relationship between rules and games-a relationship that is central to those who adjudicate sporting events. Perhaps by forgoing a pursuit of metaphysically neat categories in favor of simple descriptions of the contexts of rules, scholars and practitioners alike may begin to better understand this relationship.

To reach this conclusion, we first demonstrated inconsistent use of language and terminology regarding the categories of rules. We showed that at this point in time, little consensus exists among the philosophers using these terms and many stipulate different definitions for the same words or create new terms to fit their needs. Second, we argued that the categorical method has fundamental flaws in that rules operate in a far messier world. Inevitably this messiness dooms any account of categories for rules since such categories cannot mirror the complex and overlapping nature of the reality of game rules. This flaw explains why philosophers never could agree on the definitions of categories since the terms always failed to accurately describe all rules in all situations. The problem was not finding the right categories, but that no set of categories could ever do the work philosophers were demanding of it. While some benefit has emerged from this rule literature, it is doubtful that such a categorical approach to game rules could ever single-handedly help scholars better interpret Suárez's handball and other complex cases.

Instead, we have suggested a better way to study rules: through contextual descriptions. Contextual descriptions are ways in which philosophers examine games to see how a rule operates during the game. In other words, we ought to describe rules based on the way that officials, players, and coaches are using rules within specific contexts. While the majority of the categories used by followers of Searle provide good functional descriptions as well, they are not the only descriptions that exist. Practicing contextual descriptions provides sport philosophers with many advantages. Transforming many of the categories of previously mentioned sport philosophers such as Searle, Suits, D'Agostino, Reddiford, Meier, Morgan, Torres and Kretchmar into descriptions of the contexts of rules can better illustrate game rules, thus providing a better understanding of the operation of rules. When we applied such functional descriptions to Suárez's example, we found that the categories scholars had previously defined provided valuable shorthand for isolating 
essential philosophical questions. Moreover, with such a pluralistic understanding of game rules, the conceptual disagreement among sport philosophers over the operation of rules within games dissolves, leaving in its place a more useful paradigm for understanding complex issues in sport.

\section{Notes}

1. Of the authors we review in the following pages, D'Agostino (1), Reddiford (8), Meier (6), Morgan (7), Torres (14), and Kretchmar (3) explicitly reference Searle's work and use his terminology as a basis for their ideas (D'Agostino's reference is in an endnote). Suits (13), the only other author whose work we review, makes no reference to Searle in his text or footnotes. It should be added, though, that Suits has no bibliography and makes only a few footnotes in his entire book.

2. We will refer to the "Searlean" paradigm throughout the paper as a term that expresses both a linguistic and a conceptual framework. The Searlean paradigm expresses a framework that utilizes the terms "constitutive" and "regulative" to explain rules, and it does so from a categorical viewpoint.

3. Meier gives three groups of examples of auxiliary rules. They are: rules of safety; rules regarding empirical characteristics such as sex, weight, or age; and arbitrary restrictions on participation.

4. While, with this contrast from Searle's constitutive/regulative distinction, it might be said that Morgan is using the terms to mean something entirely different, he is still using the same terms as Searle and even references the latter by saying, "This, I take it, is the gist of Searle's claim that the "constitutive rules constitute (and also regulate) an activity the existence of which is logically dependent on the rules"' (7):* p. 53).

5. On this topic, Torres argues that "even with these practical complications [of constitutiveregulative overlap], the constitutive-regulative distinction is still useful in describing distinct legislative needs related to game playing" (14. Torres, C. R. "What Counts as Part of a Game? A Look at Skills." Journal of the Philosophy of Sport, XXVII 2000, 81-92.

6. We would like to thank a reviewer for bringing this issue to our attention.

\section{References}

1. D'Agostino, F. The Ethos of Games. Philosophic Inquiry in Sport, 1995, pp. 42-49.

2. Dworkin, R. Taking Rights Seriously. London: Duckworth, 1977.

3. Kretchmar, R.S. "A Functionalist Analysis of Game Acts: Revisiting Searle." Journal of the Philosophy of Sport, XXVIII, 2001, 160-172.

4. Loland, S. Fair Play in Sport: A Moral Norm System. London, New York: Routledge, 2002.

5. McFee, G. Sport, Rules, and Values: Philosophical Investigations into the Nature of Sport. London: Routledge, 2004.

6. Meier, K.V. "Restless Sport." Journal of the Philosophy of Sport, XII, 1985, 64-77.

7. Morgan, W.J. "The Logical Incomatibility Thesis and Rules: A Reconsideration of Formalism as an Account of Games." Philosophic Inquiry in Sport, 1995, 50-63.

8. Reddiford, G. "Constitutions, Institutions, and Games." Journal of the Philosophy of Sport, XII, 1985, 41-51.

9. Russell, J. “Are Rules All an Umpire Has to Work With?” Journal of the Philosophy of Sport, 26(1), 1999, 27-49. 
10. Searle, J. ““"How to Derive "Ought” from “Is”.” The Philosophical Review, 73(1), 1964, 43-58.

11. Searle, J.R. Speech Acts: An Essay in the Philosophy of Language. London: Cambridge U.P., 1969.

12. Simon, R.L. Fair Play: The Ethics of Sport. Boulder, CO: Westview Press, 2010.

13. Suits, B. The Grasshopper: Games, Life and Utopia, Peterborough, Ont.: Broadview Press, 2005.

14. Torres, C.R. "What Counts as Part of a Game? A Look at Skills." Journal of the Philosophy of Sport, XXVII, 2000, 81-92.

15. Wittgenstein, L., and Anscombe, G.E.M. Philosophical Investigations. The English Text of the. 3rd ed. New York: Macmillan Pub. Co., Inc., 1968. 